The XRDS blog highlights a range of topics from conference coverage, to security and privacy, to CS theory. Selected blog posts, edited for print, are featured in every issue. Please visit xrds.acm.org/blog to read each post in its entirety. If you are interested in joining as a student blogger, please contact us.

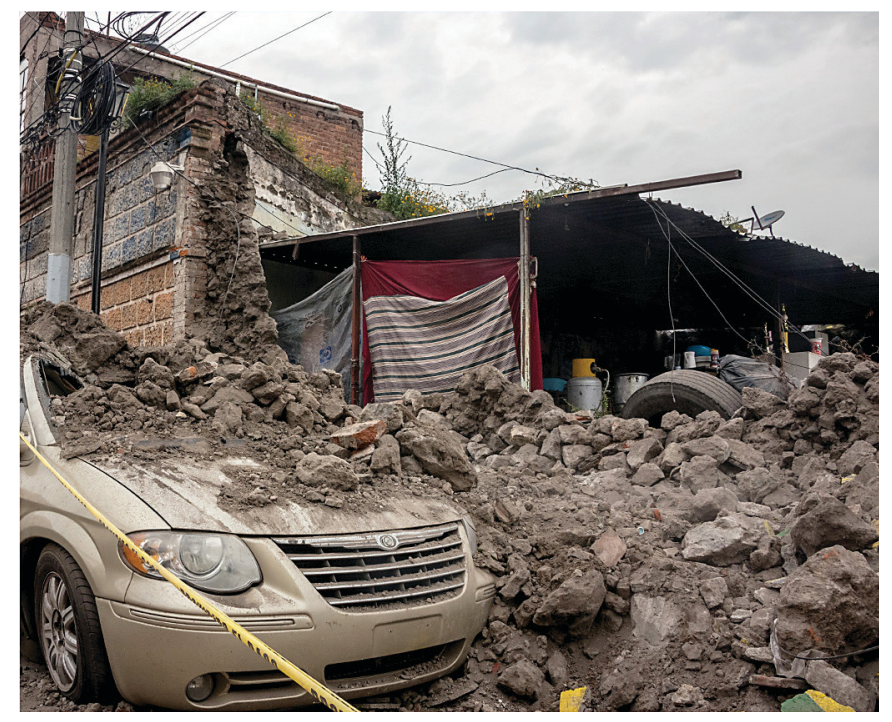

\section{On Earthquakes, Lakes, and Sensors}

\section{By Gunnar Wolf}

I live in Mexico City, one of the largest cities in the world. As all large cities, it has its ghastly demons. I am willing to argue the one lying below it makes Mexico City very unique in the world. We live atop what remains of a lake. Of course, it is not visible. Our city is not Amsterdam or Venice; where the water is embraced. Instead we seem to hide it, as if we are ashamed.

There is a small surviving fraction of the once great Lake Texcoco in the touristic borough of Xochimilco, which is in the southeast, and a wider region in the northeast that refuses to go away despite being historically ignored. The lake, however invisible, is far from dry. Although it is mostly mud, it does contain some water pockets that are harvested to deliver running water to our 22 million inhabitants. An impressive set of aqueducts also brings water from more than 400 kilometers away.

This would make for nice trivia, but there is more to it: Mexico is a seismically active country. It sits at the meeting point of four major tectonic plates; along our Pacific coastline, the Cocos plate is struggling to get under the North America and Caribbean plates. Further north, the Pacific plate is sliding north, dragging the Baja California peninsula along with it.
Just what does "seismically active" mean? According to the National Seismologic Service, we had more than 15,000 earthquakes in $2016 .{ }^{1}$

Of course, the vast majority are so weak they can only be felt locally, if at all. Usually, local earthquakes under a magnitude of six pose very little danger. In 2016, only six earthquakes over said magnitude were registered in Mexico. Not to downplay them (there was real danger and harm to people and property), but only one of them happened within 500 kilometers of Mexico City.

Last year, within two weeks time, we had two major earthquakes. On September 7th, we had a magnitude 8.2 earthquake in southeastern Mexico, close to Chiapas, Oaxaca, and the Guatemalan border. This was the strongest earthquake in the region in more than a century. The first reports were quite calm, but slowly we learned about the devastation it brought to our poorest states. Less than two weeks later, on the anniversary of the September 19, 1985 earthquake that truly devastated Mexico City, we experienced a rather atypical earthquake - a magnitude 7.1 earthquake with an inland epicenter.

All in all, the inhabitants of Mexico City were as well prepared as we could be for this kind of threat. After the terrible death toll of the 1985 earthquake, an early seismic alert network was established. Given that most often the epicenters are at the meeting point of the tectonic plates, sensors along the coast would be able to alert the population with enough anticipation to reach a safe place. This system, operated by the Seismic Instrumentation and Recording Center was started in 1989, with 12 stations along the coast directly south of Mexico City. Today it has 97 monitoring stations along the Pacific coastline. Current and historic details on this alert network are available at http://www.cires.org.mx/sasmex_es.php.

In Mexico City and Oaxaca City, the system is connected to alarm towers for relatively thorough coverage. Other cities sound the alarm over all radio stations, but do require a radio to be turned on to be effective. For an earthquake hitting close to midnight as we had on September 7th, I don't expect many people outside the capital would have reacted to it on time. There are plans to deploy alarm towers in other cities that can be potentially affected, but the work has not begun. The September 19th earthquake's epicenter was too far north for this early warning system to be of use-I remember hearing the alarms while we were already rushing down the stairs.

So, going back to the beast underneath Mexico City: The reason I started by explaining the city is built over a lake

1 http://www.ssn.unam.mx/sismicidad/mapas-de-sismicidad-anual/ 


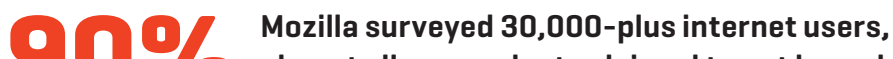 almost all respondents claimed to not know how to protect themselves online.}

is because it acts as seismic wave amplifier. The New York Times produced a very clear graphic simulation of this effect [1]. Seismic waves quickly lose strength as they travel away from their epicenter, but our jelly-like soil can increase and lengthen their effect, reflecting wavefronts that create spikes in the movements. (Do note, the New York Times' simulation does not correspond to any of the recent earthquakes.) Completely in consonance with what the simulation shows, the latest earthquake hit when I was at the university, southwest of the lake. We felt this as a relatively short movement, between 30 and 40 seconds long. But people in the center of the city reported it to be well over a minute.

I prepared a map showing the buildings that collapsed (see Figure 1), superimposing the list of coordinates registered in the following collaborative mapping document (http://bit.ly/rescateMX), which I then processed using OpenStreetMap's umap tool (http://u.osmfr.org /m/173927/\#12/19.3999/-99.1001).

I overlayed the resulting image by hand with a map of the lake from 1519, available in Wikipedia. As you can see in the resulting image, most of the destroyed buildings are almost perfectly aligned with the western edge of the

Figure 1. A map of the collapsed buildings after the September 19, 2017 earthquake, superimposed over a map of Lake Texcoco with its 16 th century borders.

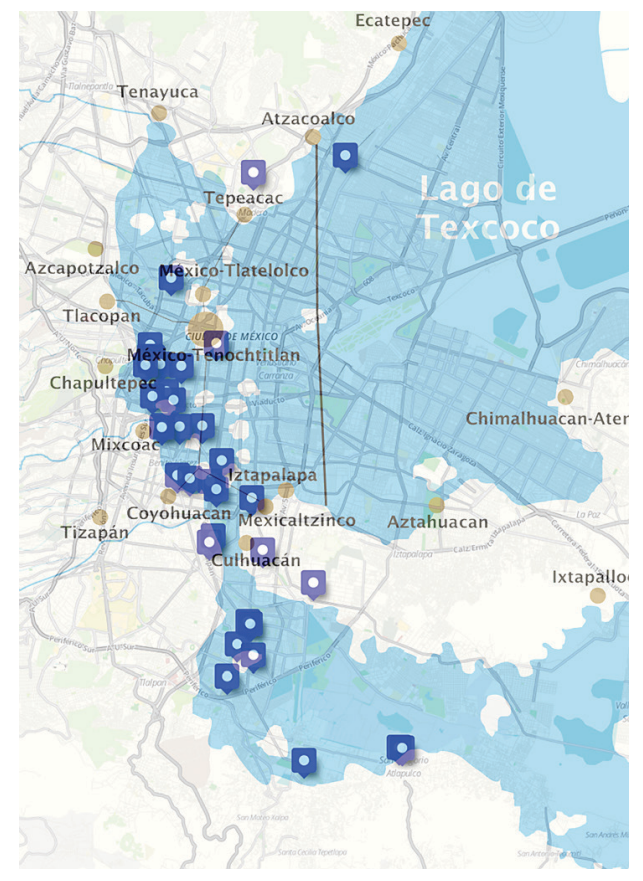

central part of the lake, where the waves broke against the mountain ridge that separates the Valley of Mexico from Toluca.

Living atop a monster requires us to constantly pay attention, to be aware of the particularities of our land. I find early warning systems one of the greatest contributions our country has done. For more than a decade, it was the only one in the world. Now similar systems have been deployed nationwide in Japan and Taiwan, and in regions of Canada, the United States, and Romania.

Hundreds of millions of people live in seismically active regions. Japan's implementation includes EEW broadcasts as well as mandated modifications to FM radio and mobile phone systems, to provide warnings and alert users before the emergency potentially damages infrastructure and saturates communications. The system alerts people without requiring wide infrastructure deployment. The sensor network performs real-time signal analysis to quickly alert the population and give as much information as possible to understand the phenomenon's origin and know how to respond.

Our field of study provides ample opportunities to help society with implementations such as the early warning systems. The amount of data the sensors generate are an invitation to study more to understand earthquakes; the importance of a reliable alert system can save thousands of lives. There is a lot we, as computing professionals, can do. We can work to design and implement new ways to deliver notifications, even in towns that do not have alert towers. We can create technology to transmit better and more reliable information in the aftermath of an earthquake. We can utilize our ability to form mesh-based networks so communications remain fully functional. These areas are well within our field, and should inspire us to contribute to a greater good.

\section{References}

[1] Watkins, D. and White, J. Mexico City was built on an ancient lake bed. That makes earthquakes much worse. New York Times [Sept. 22, 2017]; https://www.nytimes. com/interactive/2017/09/22/world/americas/mexico-city-earthquake-lake-bedgeology.html

Biography

Gunnar Wolf is pursuing a M.Sc. degree in information security at Instituto Politécnico Nacional [Escuela Superior de Ingeniería Mecánica y Eléctrica], and teaches at the undergraduate level at the National Autonomous University of Mexico [Facultad de Ingeniería]. He is a free software advocate, and a developer in the Debian project. As a systems and network administrator for the Economics Research Institute [UNAM], he has had the opportunity to do research on topics that include the social aspects of free software projects. 